\title{
Nieva Ocampo, Guillermo, González Fasani, Ana Mónica y Chiliguay, Alejandro Nicolás (Coords.), La Antigua Gobernación del Tucumán. Política, sociedad y cultura (s. XVI al XIX), Milor, Salta, 2020
}

María Lorena Peralta* Mariana Piermarini**

Esta obra fue publicada en 2020 con el patrocinio del "Instituto Universitario La Corte en Europa” (IULCE) de la Universidad Autónoma de Madrid y del Proyecto N 2.354: “Agentes del gobierno en el mundo hispano. Microanálisis del poder monárquico (ss. XV-XVIII)" del Consejo de Investigación de la Universidad Nacional de Salta (CIUNSa). Su coordinación estuvo a cargo de Guillermo Nieva Ocampo (CONICET/Universidad Nacional de Salta), Ana Mónica González Fasani (Universidad Nacional del Sur) y Alejandro Nicolás Chiliguay (CONICET/Universidad Nacional de Salta). Además participan como autores: Juan Jiménez Castillo (Universidad Autónoma de Madrid), Adriana del Valle Báez (Universidad Nacional de Salta), Giovanni Zampar (Universidad Nacional de Salta), Daniela Alejandra Carrasco (Universidad del Salvador), Jezabel Borella (Universidad Nacional de Salta), Marcelo Correa (CONICET/Universidad Nacional de Salta), Javier Hipólito Villanueva (Universidad de los Andes), Bárbara Aramendi (CONICET/Universidad Nacional de Salta), Gabriela Lupiañez (Universidad

* Universidad Nacional de Córdoba. E mail: marialorenaperalta4@gmail.com

** Universidad Nacional de Córdoba. E mail: maripier97@gmail.com 
Nacional de Tucumán), Gustavo Bazán (Universidad Nacional de Salta), Ana María Martínez de Sánchez (CIESC. CONICET/ Universidad Nacional de Córdoba), Silvano G. A. Benito Moya (CONICET/Universidad Nacional de Córdoba), María Luciana Llanpur (Universidad Nacional de Jujuy), Nora Siegrist (CONICET/ Pontificia Universidad Católica Argentina), Marisa Restiffo (Universidad Nacional de Córdoba), Leonardo Waisman (CONICET/ Universidad Nacional de Córdoba) y Cecilia Cornejo (Universidad Católica de Salta).

Según explican los coordinadores, el texto se pensó y diseñó con calidad y formato de "manual general" con la finalidad de proporcionar un relato histórico claro, simple y completo sobre la historia de la antigua Gobernación del Tucumán. Principalmente, su lectura está destinada a docentes de nivel medio, estudiantes universitarios y a todos aquellos lectores pertenecientes a un público interesado en esta temática.

A esa valiosa característica del texto reseñado se suman otras dos virtudes que resulta necesario destacar. Por una parte, que la historia de ese territorio está pensada y escrita en el contexto global de la Monarquía hispánica, lo que hace que el estudio expanda sus horizontes más allá de una historia a escala local o regional. Por otra parte, en su elaboración participaron diversos autores de larga trayectoria quienes contribuyen a dar cuenta desde una mirada multidimensional de los numerosos aspectos que se incorporan. Los mismos se expresan en un lenguaje accesible, pero desde una plataforma de información densa a partir de investigaciones originales y de base. Así, este manual corresponde a una obra académica cuyo objetivo es proporcionar un trabajo de síntesis y difusión para dar cuenta de todos aquellos aspectos de la antigua Gobernación del Tucumán a escala de la Monarquía española durante estos siglos.

En líneas generales, el texto se divide en cuatro partes vinculadas principalmente con la vida política y social de este territorio durante los siglos XVI y principios del XIX. Está compuesto por dieciocho capítulos en total y su estructura interna es similar en cada uno de los mismos, yendo de lo general a lo particular y presentando al principio un sumario, luego el desarrollo de diferentes apartados según la temática abordada y, al final, un apéndice documental junto con la bibliografía utilizada. Por sus características, el libro no cuenta con citas a pie de página pero está enriquecido con mapas, imágenes, croquis, fotografías y/o estadísticas que favorecen una completa explicación. 
De manera general, sigue un orden cronológico, sobre todo en las tres primeras partes en las que desde una "temporalidad larga" se desarrollan sus contenidos abordando sucesivamente los siglos XVI, XVII y XVIII. En la última sección se cambia la estrategia de escritura, tomando esa misma temporalidad - y en menor medida aspectos del siglo XIX - como bloque, atravesándola con problemas de diferente contenido los que desarrollaremos más adelante. Por otro lado, el trabajo abarca una amplia territorialidad en sus estudios incluyendo paralelamente los procesos ocurridos en la Metrópoli y en las distintas regiones de América. Asimismo, es importante resaltar que desde una perspectiva historiográfica renovada este trabajo pretende revalorizar la acción de los individuos como gestores de estructura, considerando los diversos vínculos sociales y sus espacios sociales, políticos, económicos y culturales de conformación.

Respecto al análisis político, la obra incluye las características y evolución de los distintos reinados de la Monarquía hispánica articulándolos al proceso de consolidación de su poder en las Indias, especialmente en el Tucumán. Así, encontramos las transformaciones en el siglo XVI durante el reinado de Carlos I y la consolidación de la Monarquía Universalis con la expansión ultramarina de Europa, el proceso de descubrimiento, expediciones y colonización en América teniendo en cuenta las características en el reino del Perú (Jiménez Castilla, J. Capítulo I). Luego, se analiza el reinado de su sucesor, Felipe II, heredero de un territorio donde "nunca se ponía el sol” y el proceso de pacificación (Jiménez Castilla, J. Capítulo I y González Fasani, A. M. Capítulo II). Posteriormente, se estudian el reinado de Felipe III en el siglo XVII en el tránsito hacia una Monarquía católica, junto con la conformación de los Consejos y el surgimiento del valido (Carrasco, D. A. Capítulo IV); los tiempos de Felipe IV, incluyendo la figura del Conde Duque de Olivares (Nieva Ocampo, G. Capítulo V y Borella, J. Capítulo VI); y el final de la dinastía de los Austrias en la península con Carlos II (Nieva Ocampo, G. Capítulo VII).

Un aspecto importante dentro del análisis político es la consideración del papel del clero, sobre todo la figura de los obispos como agentes locales en la toma de decisiones y en la organización política, social y económica de la Gobernación del Tucumán (Báez. A y Zampar, G. Capítulo III; Carrasco, A. Capítulo IV; Nieva Ocampo, G. Capítulo V y Nieva Ocampo, G. \& González Fasani, A. M. Capítulo VIII). 
Se reseña también la evolución de los distintos organismos políticos implantados como las audiencias, virreinatos, cabildos y corregimientos en las nuevas ciudades, detallando las numerosas figuras y recorridos de virreyes, gobernadores y encomenderos entre otros, que formaban parte de una particular élite política en los territorios tucumanos (Castillo, J. Capítulo I; González Fasani, A. Capítulo II; Chiliguay, A. Capítulo IX y Lupiañez, G. Capítulo XII). De igual modo, cabe destacar que en la mayoría de los capítulos se resaltan los distintos sistemas de poder y relaciones políticas propias de la Monarquía que se replican en los territorios de ultramar conquistados, con especial relevancia el sistema cortesano y el sistema familiar a partir de las numerosas alianzas, clientelismo y patronazgo de las élites locales como forma de gobierno y de articulación política y las consecuentes luchas o rivalidades para la toma de decisiones (Castillo, J. Capítulo I; González Fasani, A. M. Capítulo II; Carrasco, D. Capítulo IV; Nieva Ocampo, G. Capítulo V; Borella, J. \& Correa, M. Capítulo VI; Nieva Ocampo, G. \& Villanueva, J. H. Capítulo VII; Nieva Ocampo, G. \& González Fasani, A. M. Capítulo VIII y Chiliguay, A. Capítulo IX). Se subrayan asimismo las dificultades y obstáculos del contexto bélico o resistencias en las Indias y la situación en la Metrópoli con sus frentes de guerra en Europa y sus dificultades financieras (Castillo, J. Capítulo I; González Fasani, A. M. Capítulo II; Carrasco, D. Capítulo IV; Nieva Ocampo, G. Capítulo V; Borella, J. \& Correa, M. Capítulo VI; Nieva Ocampo, G. \& Villanueva, J. H. Capítulo VII y Nieva Ocampo, G. \& González Fasani, A. M. Capítulo VIII). Se incorpora también un enfoque más centrado en las dinámicas sociales desencadenadas durante el proceso de conquista y colonización y cómo las mismas constituyen un esencial factor de integración de las élites locales indígenas en sistemas de alianzas con los conquistadores mediante enlaces matrimoniales, estrategia propia del Antiguo Régimen. A su vez, junto con numerosos ejemplos, se especifica el perfil social de los españoles y de la sociedad encomendera tucumana, la importancia de la familia como elemento estructural de esta sociedad así como las oportunidades para crecer socialmente y prosperar a través de los lazos de parentesco, amistad y dependencia o por las inmigraciones (Jiménez Castilla, J. Capítulo I; González Fasani, A. M. Capítulo II; Carrasco, D. A. Capítulo IV; Nieva Ocampo, G. Capítulo V; Borella, J. \& Correa, M. Capítulo VI y Nieva Ocampo, G. \& Villanueva, J. H. capítulo VII). Varios autores enfatizan la relevancia de aquellos que formaban parte de la Iglesia y la 
posición del clero en la sociedad tucumana (Báez, A. \& Zampar, G. Capítulo III; Carrasco, D. A. Capítulo IV; Nieva Ocampo, G. \& Villanueva, J. H. Capítulo VII y Nieva Ocampo, G. \& González Fasani, A. M. Capítulo VIII). En esa misma línea se describe cómo la sociedad, debido a las características fronterizas y la orientación agropecuaria del Tucumán, fue laxa y abierta propiciando un escenario de promoción social, económica y de mestizaje (Nieva Ocampo, G. Capítulo V). Por otro lado, se señala la figura del vecino como residente, generalmente propietario de encomiendas y ocupando oficio en el Cabildo (González Fasani, A. M. Capítulo II y Borella, J. \& Correa, M. Capítulo VI). Además, se subraya cómo la población local se renueva con la reducción de la proporción de indígenas hacia el siglo XVII y el creciente número de europeos que se suman a esa sociedad (Nieva Ocampo, G. \& Villanueva, J. H, capítulo VII). Más allá de las estrategias de integración de los nuevos reinos a la Monarquía, el libro incluye el análisis de las numerosas resistencias y revueltas que se manifestaron en los diferentes pueblos nativos del territorio, los mejores ejemplos son las guerras Calchaquíes o los movimientos en los espacios de frontera del Chaco y las pampas (Nieva Ocampo, G. Capítulo V; Borella, J. \& Correa, M. Capítulo VI y Nieva Ocampo, G. \& Villanueva, J. H. Capítulo VII).

Una vez arribados al siglo XVIII, se abordan temas como la política indiana durante el reinado de Felipe V, las disputas de poder que se generaron en el Virreinato del Perú (Chiliguay, A. Capítulo IX), la administración de la región en la segunda mitad del siglo XVIII con un recorrido por el contexto político peninsular, las Reformas Borbónicas, las complejidades de la Real Hacienda o la expulsión de los jesuitas entre otros (Aramendi, B. Capítulo XI).

En este relato no queda afuera el momento revolucionario, la autonomía de esos nuevos gobiernos y su representación así como la difícil coyuntura de 1815, el reconocimiento de un nuevo poder, las resistencias de los pueblos al Estatuto Provisional, el Congreso de Tucumán y la declaración de la independencia (Lupiañez, G. Capítulo XII).

La cuarta parte del libro se vincula al aspecto cultural e indaga sobre la vida cotidiana (Martínez de Sánchez, A. Capítulo XIV), abordando temas como la familia, sociabilidades, vestimenta, tiempo de fiestas y de ocio, usos y costumbres domésticos, el abasto de la mercadería de la población, la condición de la mujer en los siglos XVII 
y XVIII en el territorio tucumano a través de las dotes y las formas de la educación y la moral (Siegrist, N. Capítulo XVI). Se incluye nuevamente en este apartado la centralidad del clero en la vida cultural, destacándose aspectos no sólo de la actividad pastoral de los religiosos sino también de las misiones de las distintas órdenes, sobre todo la de los jesuitas, así como su función educativa en los colegios y en la Universidad. Asimismo, se desarrolla la presencia de conventos femeninos, cofradías y las práctica de numerosas devociones (Báez, A. \& Zampar, G. Capítulo III y Nieva Ocampo, G. \& González Fasani, A. M.. Capítulo VIII) como así también las transformaciones eclesiales tanto en el virreinato del Perú durante el reinado de los Austrias (Báez, A. \& Zampar, G. Capítulo III; Carrasco, D. A. Capítulo IV y Nieva Ocampo, G. \& González Fasani, A. M. Capítulo VIII) como en el período borbónico (Chiliguay, A. Capítulo X) con la expulsión de los jesuitas durante el episcopado de Manuel Abad Illiana. Se incorpora el estudio de la creación de la diócesis de Salta y la de Córdoba y cómo la Iglesia se posiciona frente a los avatares revolucionarios (Zampar, G. \& Bazán, G. Capítulo XIII).

La educación es otro de los temas que se abordan dentro del eje cultural (Nieva Ocampo, G. \& González Fasani, A. M. Capítulo VIII; Benito Moya, S. \& Llapur, M. Capítulo XV), en el mismo se analiza la educación en el Antiguo Tucumán examinando la enseñanza elemental, los espacios destinados para la educación, y la oferta universitaria. Las prácticas musicales también tendrán un lugar en este eje cultural, indagando en las sociedades, las costumbres y las personas que poblaban estos territorios (Restiffo, M. \& Waisman, L. Capítulo XVII). De igual manera, se analiza el arte a través de una descripción de cómo era o debía ser la arquitectura doméstica, política o eclesiástica en la época, como así también el arte jesuítico en Córdoba (Cornejo, C. Capítulo XVIII).

En el libro se presentan algunas de las características de la economía de la época en la región. En este sentido, se mencionan diversas medidas económicas y fiscales en este proceso de administración de los nuevos reinos. Por otro lado, se subraya la relevancia de la explotación de la tierra como forma de riqueza, especialmente con el cultivo y la cría de mulas y ganado vacuno, lo que llevó a la encomienda de servicio consolidado en el siglo XVII, y las actividades mercantiles y la formación de un mercado interno de mercancías entre los diferentes espacios peruanos. Esta obra incluye las numerosas 
crisis económicas que atravesaron a lo largo del período estudiado (González Fasani, A. M. Capítulo II; Carrasco, A. Capítulo IV; Nieva Ocampo, G. Capítulo V; Borella, J. \& Correa, M. Capítulo VI y Nieva Ocampo, G. \& Villanueva, J. H. Capítulo VII).

Desde el inicio hasta el final del manual hay una lectura amena, invitando al lector a introducirse en el conocimiento de la historia de esta Gobernación en sus diferentes aspectos, sin descuidar la multitemporalidad ni la multiterritorialidad. Los diferentes autores avanzan en sus análisis e investigaciones enriqueciendo cada capítulo con fuentes epocales que pueden ser de utilidad a docentes en el desarrollo de sus clases, a estudiantes a introducirse en la temática o a quien esté interesado en la historia de la región. Cada capítulo presenta su tema con explicaciones generales y de fácil acceso, que pueden servir de puntapié para el inicio de futuros estudios en profundidad. En suma, es un libro sumamente necesario y útil dentro de la historiografía al conseguir englobar de forma sencilla y sintética la historia del conjunto de la Gobernación del Tucumán en el marco de la Monarquía española. 